\title{
Physicochemical Evidence for the Adsorption of Extract of Jacaranda mimosifolia on Steel Against Corrosion in Acid Medium
}

\section{KAVITHA ROSE ${ }^{1,2}$, MONIKANDON SUKUMARAN ${ }^{3}$, KESAVAN DEVARAYAN $^{1,4 *}$, GOPIRAMAN MAYAKRISHNAN ${ }^{5}$ and SANKAR ARUMUGAM ${ }^{2, *}$}

\author{
'Department of Chemistry, Dhirajlal Gandhi College of Technology, Salem, India. \\ 2Department of Chemistry, Kandasamy Kandar's College, Salem 638182, India. \\ ${ }^{3}$ Department of Basic Engineering, College of Fisheries Engineering, \\ Tamil Nadu Fisheries University, Nagapattinam 611 001, Tamil Nadu, India. \\ ${ }^{4}$ Department of Basic Sciences, College of Fisheries Engineering, \\ Tamil Nadu Fisheries University, Nagapattinam 611 001, Tamil Nadu, India. \\ ${ }^{5}$ Department of Applied Bioscience, College of Life \& Environment Science, \\ Konkuk University, Seoul, South Korea. \\ ${ }^{*}$ Corresponding author E-mail: dev.kesavan@ gmail.com
}

http://dx.doi.org/10.13005/ojc/320444

(Received: July 26, 2016; Accepted: August 20, 2016)

\begin{abstract}
For the first time, the homogeneous adsorption of ethanolic extract of Jacaranda mimosifolia green inhibitor is evaluated for inhibition of steel corrosion in acid environment. The inhibitive properties are evaluated by means of weight loss measurements, polarization studies, and electrochemical impedance spectroscopy. A maximum of $96 \%$ of inhibition efficiency is achieved by using $500 \mathrm{ppm}$ of the green inhibitor. The mechanism and nature of adsorption of inhibitor on the surface of steel are evidenced by Langmuir adsorption isotherm and energy dispersive $\mathrm{X}$-ray spectral elemental mapping.
\end{abstract}

Keywords: Adsorption; Elemental Mapping; Evidence; Jacaranda mimosifolia; Green Inhibitor; Steel.

\section{INTRODUCTION}

Steel corrosion in acidic solutions has become an intensive academic research topic since it can greatly influence the economy of any country. It has been reported by several researchers that steel corrosion can be controlled by the use of suitable inhibitors. Inorganic inhibitors such as phosphates, chromates, and arsenates were found to be effective against the corrosion of steel in acidic medium. However, the major disadvantage of using these inorganic inhibitors is their toxicity and nonecofriendliness. Organic inhibitors are one of the alternatives to inorganic inhibitors. It is well known 
that the first step of inhibitive action of an inhibitor is adsorption of the additive on to the metal surface. For this purpose, inhibitors with polar functions with heteroatoms such as nitrogen, oxygen, and/or sulphur preferable ${ }^{1}$.

In recent years, inhibitors of plant origin have exhibited excellent inhibition properties against the steel corrosion ${ }^{1,2}$. Inhibitors from natural resources such as plants are interesting since they are abundant, economical, and environmentally friendly. In order to explore the efficient organic inhibitors, the authors have studied several synthetic as well as plant-based green inhibitors against the corrosion of steels in different media ${ }^{3-6}$. In an effort to contribute to the current interest on development of the ecofriendly inhibitors, in this study, the authors examined the ethanolic leaf extract of Jacaranda mimosifolia (JM) against the corrosion of steel in 1.0 M HCl. JM (Sakaranda in Tamil) belongs to Bignoniaceae family and an habitat of tropical areas such as India, South America, Brazil, and South Africa. Different parts of the JM were evaluated for applications such as trace metal and dye adsorption from contaminated water ${ }^{7-9}$. In view of abundance, environmental friendliness, and economy, in the present study, the ethanolic extract of JM is evaluated as an active steel corrosion inhibitor in an acid medium. The inhibition efficiency of JM extract is studied by means of gravimetric weight loss and electrochemical studies. The energy dispersive X-ray spectroscopic measurement also used to observe the surface of the inhibitor adsorbed-steel.

\section{EXPERIMENTAL}

\section{Preparation of Inhibitor}

The green inhibitor was prepared by a procedure similar to our previous reports ${ }^{8,9}$. In brief, the shade-dried leaves of JM (1 kg) were powdered finely and soaked in $95 \%$ ethanol for 3 days. Then the solvent was removed under vacuo to obtain oily precipitate $(26 \mathrm{~g})$.

\section{Preparation of Test Solutions}

1.0 $\mathrm{M} \mathrm{HCl}$ solutions were prepared using concentrated $\mathrm{HCl}$ (Merck, $\mathrm{AR}$ ) using double distilled water. The concentration range of the JM extract was 100-500 ppm. The acid solution without inhibitor solution is taken as blank solution. The acid solutions were prepared freshly just before each experiment.

\section{Weight Loss Studies}

The chemical composition of the steel specimens used in this study was C, 4.93\%; Mn, $1.09 \%$; $\mathrm{Si}, 1.78 \%$, and the remainder being $\mathrm{Fe}$. At first, the specimens were abraded using emery sheets of different grades and then washed in distilled water and degreased in acetone followed by drying at room temperature. The weight of the specimen was noted before $\left(W_{0}\right)$ and after $(W)$ blank experiment using $1.0 \mathrm{M} \mathrm{HCl}$ and the experiments were performed in triplicates. Using the following equations 1-3, the inhibition efficiency (IE\%), surface coverage (q), and corrosion rates (CR) were calculated.

$$
\begin{aligned}
& I E \%=\frac{w_{0}-W}{w_{0}} \times 100 \\
& \theta=I E \% / 100 \\
& C R=\frac{w_{o}}{A t D}
\end{aligned}
$$

Where, $C R$ - corrosion rate $(\mathrm{mm} / \mathrm{y}), W_{o}$ - weight difference $(\mathrm{g})$ before and after weight loss measurements; $A$ - exposed area of the specimen, $t$ - immersion time (h), and $D$ - density of the specimen $\left(\mathrm{g} / \mathrm{cm}^{3}\right)$. The weight loss values were used to plot adsorption isotherms such as Langmuir adsorption isotherm and to calculate the thermochemical parameters.

\section{Electrochemical Studies}

Electrochemical experiments were carried out in a conventional three electrode cell assembly with steel having $1 \times 1 \mathrm{~cm}^{2}$ area as a working electrode, platinum as a counter electrode, and a saturated calomel electrode as reference. The thermodynamic Tafel polarization and electrochemical impedance spectroscopic (EIS) measurements were carried out using $\mathrm{CH} 6043 \mathrm{~b}$ electrochemical analyzer. The EIS and Tafel polarization measurements were performed similar to our previous studies 8,9 .

\section{Surface Analysis and Elemental Mapping}

The surface morphology and energy dispersive X-ray spectral analysis (EDS) of specimens after treatment in blank solution and with inhibitor were observed under a JSM-5900 scanning electron microscopy coupled with EDS. 


\section{RESULTS AND DISCUSSION}

\section{Weight Loss Studies}

The weight loss data shown in Fig. 1 and listed in Table 1. The JM extract concentration was varied from 100-500 ppm. At the highest concentration of $500 \mathrm{ppm}$, the inhibitor has a highest inhibition efficiency of $92.1 \%$. This is attributed to the surface coverage of steel by the inhibitor molecules present in the JM extract. It is interesting to note that no significant inhibition was observed above $500 \mathrm{ppm}$ of the inhibitor. This may be attributed to the saturation of the surface coverage due to the presence of large quantities of inhibitor molecules that could not influence the adsorption process.

\section{Adsorption Isotherm}

Generally, the inhibition of corrosion using inhibitor molecules proceeds via either physical adsorption or chemical adsorption or both. It is imperative to understand the nature of the adsorption behavior of the inhibitor molecules. In this view, the data from weight loss measurements were evaluated to fit for different isotherms such as Langmuir, Freundlich, and Frumkin adsorption isotherms. Linear relationship was observed for the data only in the case of Langmuir adsorption isotherm (Fig.2). The Langmuir adsorption isotherm can be understood from the relationship between surface coverage and the inhibitor concentration as shown in the following equation (4).

$$
\frac{C}{\theta}=\frac{1}{\operatorname{Kads}}+C
$$

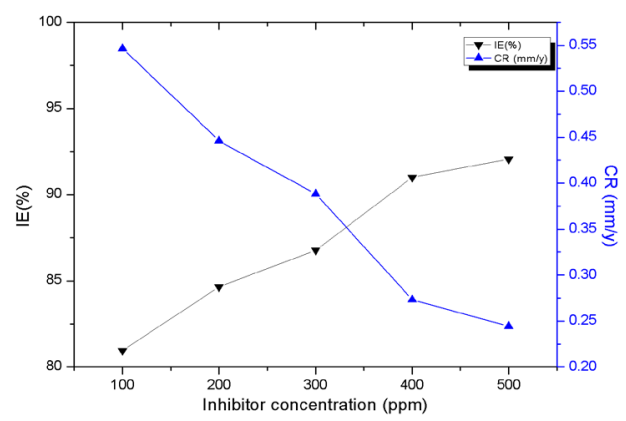

Fig.1: Effect of JM extract concentration on inhibition efficiency (IE\%) and corrosion rate (CR) at $298 \mathrm{~K}$
Where, $K_{a d s}$ is the equilibrium constant of adsorption process.

The correlation co-efficient $\left(R^{2}\right)$ for the Langmuir isotherm was 0.9995. The result indicated that the adsorption mechanism of the corrosion inhibition process in the present study obeys Langmuir adsorption isotherm. In other words, corrosion of inhibition of steel by JM extract predominantly proceeds via physical adsorption. The higher inhibition efficiency of the JM extract is attributed to the molecules present in the extract. Generally, plant extracts contain alkaloids and flavonoids ${ }^{1,7}$ which possess aromatic rings and highly electronegative atoms such as oxygen, sulphur, and/ or nitrogen in the chemical structure.

Further the data obtained from weight loss studies were subjected to equations (4) and (5) to calculated the equilibrium constant $\left(K_{a d s}\right)$ and the free energy of adsorption $\left(\Delta G_{a d s}\right)$ (Table 1$)$.

$$
\Delta G_{a d s}=-R T \ln \left(55.5 K_{a d s}\right)
$$

where $R$ is the gas constant, $T$ is the temperature, and the value of 55.5 is the concentration of water in the inhibitor solution. The values of $\Delta G_{a d}$ for all the concentration of the inhibitor was found to between -17.7 and $-19.1 \mathrm{~kJ} / \mathrm{g}$. Generally, if the $\Delta G_{\text {adsads }}$ is lesser than $-20.0 \mathrm{~kJ} / \mathrm{g}$ then the inhibition is ascertained to physical adsorption process. If the $\Delta G_{\text {adsads }}$ is greater than $-40 \mathrm{~kJ} / \mathrm{g}$ then the inhibition is due to the chemical adsorption of the inhibitor molecules on the surface of the steel. In the present study, the $\Delta G_{\text {adsads }}$ values are lesser than $-20.0 \mathrm{~kJ} / \mathrm{g}$

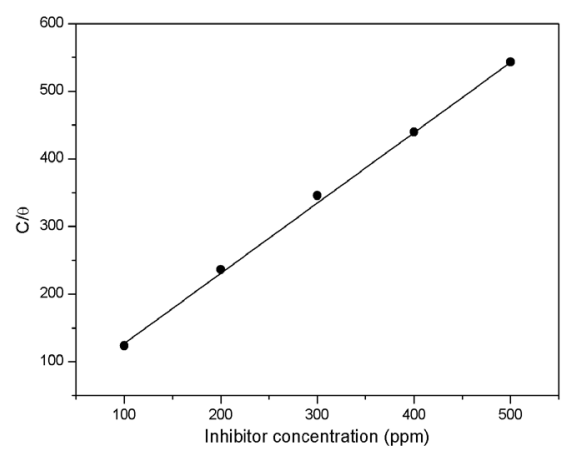

Fig.2: Langmuir adsorption isotherm 
which clearly indicates that the inhibition mechanism predominantly involved in physical adsorption ${ }^{11-13}$.

\section{Electrochemical Studies}

The Tafel polarization and the EIS studies were performed both in presence and absence of different concentrated solutions of JM inhibitor in $1 \mathrm{M}$

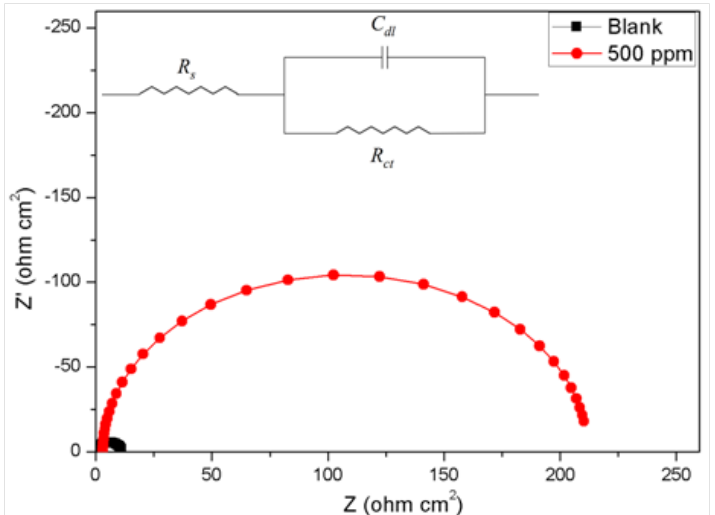

$\mathrm{HCl}$ at $298 \mathrm{~K}$. The steady-state was achieved within $2 \mathrm{~h}$. Depressed-EIS semi circles were observed for both experiments with and without 500 ppm of inhibitor (Fig.3a). The charge-transfer resistance values for blank and blank +500 ppm inhibitor were 11.1 and $211 \mathrm{ohm} / \mathrm{cm}^{2}$, respectively (Table 2). The diameter of the EIS semi-circle for blank + 500 ppm

Fig. 3. (a) Electrochemical impedance spectra and (b) Tafel polarization curve for mild steel in blank and $\mathbf{5 0 0}$ ppm of JM inhibitor

inhibitor increases due to the surface coverage of steel by inhibitor molecules which prevents the attack of the $\mathrm{HCl}$ and thus decreases the conductivity. In addition, the values of double layer capacitance $\left(C_{d l}\right)$ were also calculated using the following equation (5).
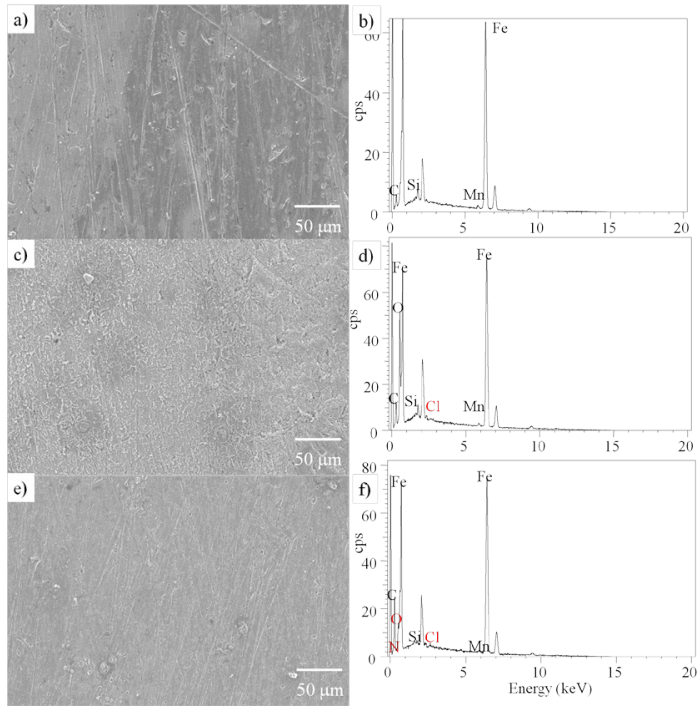

Fig. 4: SEM and ED spectrum of $(a, b)$ raw steel specimen, (c, d) steel treated in $1.0 \mathrm{M} \mathrm{HCl}$, and $(e, f)$ steel treated in inhibitor solution

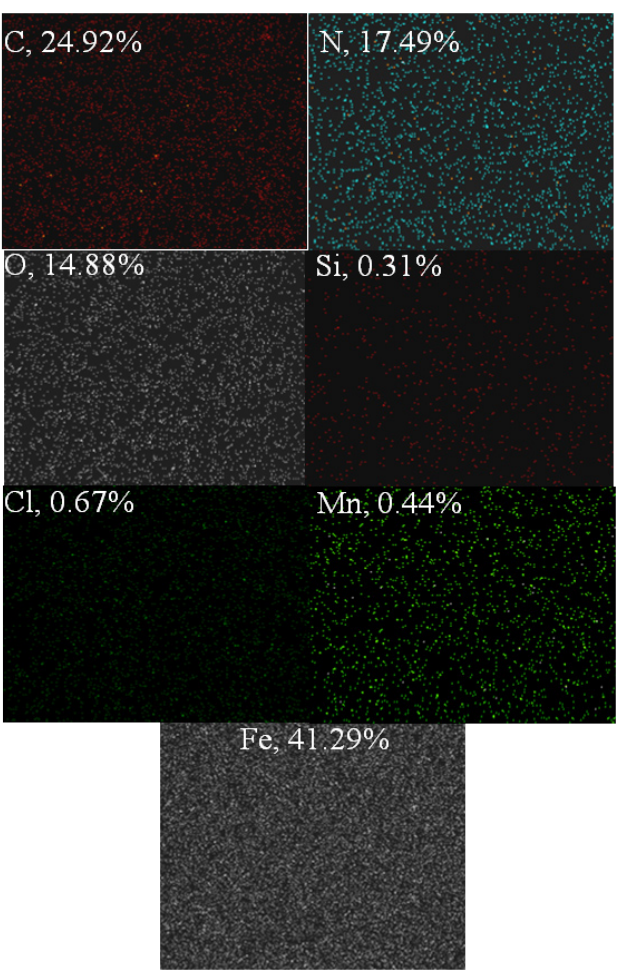

Fig.5: EDS elemental mapping of the surface of steel specimen treated in $1.0 \mathrm{M} \mathrm{HCl}$ in presence of 500 ppm of JM inhibitor solution 


$$
C_{d l}=\frac{1}{\left(2 \prod f_{\max } R_{c t}\right)}
$$

It is interesting to note that the $C_{d l}$ values of blank solution $\left(267.4 \mu \mathrm{F} \mathrm{cm}^{-2}\right)$ are higher than the solution with $500 \mathrm{ppm}$ of inhibitor $\left(7.3 \mu \mathrm{F} \mathrm{cm}^{-2}\right)$. This phenomenon can be explained by the adsorption of the inhibitor molecules on the steel surface. The adsorption of inhibitor molecules decreases the dielectric constant of steel by covering the surface which obviously led to the decrease in the double layer thickness ${ }^{14}$.

The Tafe/polarization results are presented in Fig. 3b and Table 3. The polarization curves indicated that the corrosion current values obtained for JM inhibitor were lower than the blank solution. Further, the $E_{\text {corr }}$ value between the blank and the JM inhibitor was more than $\pm 85 \mathrm{mV}$. This is ascertained to the behavior of the inhitor to suppress predominantly anodic reaction ${ }^{15,16}$.

\section{Surface Analysis}

The microscopic images and ED spectra of the abraded steel specimen, steel treated in blank solution as well as blank solution with 500 ppm of inhibitor are shown in Fig. 4. The elemental composition of these samples obtained from ED spectra are given in Table 4. Fig.4a exhibits a steel surface with scratches caused by manual polishing. Whereas, the acid-treated steel (Figure 4c) exhibits high corrosion along with the corrosion products.

Table 1: Corrosion parameters for inhibition of steel corrosion in $1.0 \mathrm{M} \mathrm{HCl}$ by JM extract at $298 \mathrm{~K}$

\begin{tabular}{|c|c|c|c|c|c|}
\hline $\begin{array}{l}\text { C } \\
\text { (ppm) }\end{array}$ & $\begin{array}{c}\text { Surface } \\
\text { Coverage }\end{array}$ & $\begin{array}{l}\text { IE } \\
\%\end{array}$ & $\begin{array}{c}\text { CR } \\
(\mathrm{mm} / \mathrm{y})\end{array}$ & $\begin{array}{c}K_{\text {ads }} \\
(\mathrm{KJ} / \mathrm{g})\end{array}$ & $\begin{array}{l}\mathrm{DG}_{\text {ads }} \\
(\mathrm{kJ} / \mathrm{g})\end{array}$ \\
\hline 0 & - & - & 2.718 & - & - \\
\hline 100 & 0.810 & 80.952 & 0.547 & 42.5 & -19.4 \\
\hline 200 & 0.847 & 84.656 & 0.446 & 27.6 & -18.3 \\
\hline 300 & 0.868 & 86.772 & 0.388 & 21.9 & -17.7 \\
\hline 400 & 0.910 & 91.005 & 0.273 & 25.3 & -18.1 \\
\hline 500 & 0.921 & 92.063 & 0.244 & 23.2 & -17.9 \\
\hline
\end{tabular}

Table 2: EIS parameters of steel specimen in presence and absence of $\mathrm{JM}$ inhibitor in $1.0 \mathrm{M} \mathrm{HCl}$ at $298 \mathrm{~K}$

\begin{tabular}{lcccccc}
\hline Inhibitor & $\begin{array}{c}\text { Concentration } \\
(\mathbf{p p m})\end{array}$ & $\begin{array}{c}\boldsymbol{R}_{c t} \\
\left(\Omega \mathbf{c m}^{2}\right)\end{array}$ & $\boldsymbol{f}_{\text {max }}$ & $\begin{array}{c}\boldsymbol{C}_{\boldsymbol{d l}} \\
\left(\boldsymbol{\mu F ~ \mathbf { c m } ^ { - 2 } )}\right.\end{array}$ & $\Phi$ & $\begin{array}{c}\text { IE } \\
\%\end{array}$ \\
\hline Blank & 0 & 11.1 & 5.38 & 267.4 & - & - \\
JM & 500 & 211 & 103 & 7.3 & 0.948 & 94.8 \\
\hline
\end{tabular}

Table 3: Tafel polarization parameters of steel specimen in presence and absence of JM inhibitor in $1.0 \mathrm{M} \mathrm{HCl}$ at $298 \mathrm{~K}$

\begin{tabular}{|c|c|c|c|c|c|c|c|}
\hline Inhibitor & $\begin{array}{c}\text { Concentration } \\
\text { (ppm) }\end{array}$ & $\begin{array}{c}b_{c}(\mathrm{mV} / \\
\text { decade) }\end{array}$ & $\begin{array}{l}b_{\mathrm{a}}(\mathrm{mV} / \\
\text { decade) }\end{array}$ & $\begin{array}{c}-E_{\text {corr }} \\
\text { (V vs SCE) }\end{array}$ & $\begin{array}{c}I_{\text {corr }} \\
\left(\mu \mathrm{A} / \mathrm{cm}^{2}\right)\end{array}$ & $\Phi$ & IE\% \\
\hline Blank & - & 5.687 & 4.292 & 0.562 & 673.3 & - & - \\
\hline Blank+JM & 500 & 5.427 & 4.639 & 0.674 & 27.9 & 0.959 & 95.9 \\
\hline
\end{tabular}


Table 4: Elemental composition of steel specimens

\begin{tabular}{lccccccc}
\hline Sample & & \multicolumn{3}{c}{ \% Composition } & & & \\
& Fe & $\mathbf{O}$ & $\mathbf{C}$ & Mn & Si & Cl & N \\
\hline Fresh steel specimen & 92.20 & 0 & 4.93 & 1.08 & 1.79 & 0 & 0 \\
Blank & 67.11 & 23.29 & 4.38 & 0.77 & 1.29 & 3.16 & 0 \\
$1.0 \mathrm{M} \mathrm{HCl}+\mathrm{JM}$ extract & 41.29 & 14.88 & 24.92 & 0.44 & 0.31 & 0.67 & 17.49 \\
\hline
\end{tabular}

The corrosion products are evidenced by ED spectra shown in Figure 4d. Meanwhile the steel treated in acid+inhibitor solution exhibited mostly smooth surface (Fig. 4e). The corresponding ED spectrum is revealed the presence of elements such as $O$ and $\mathrm{N}$ which is evident for the deposition of inhibitor molecules on the surface of the steel.

In order to further understand and visualize the adsorption behavior of the inhibitor, the surface of the steel treated in acid + inhibitor is subjected to $\mathrm{X}$-ray elemental mapping (Fig. 5). The results showed that the elements $\mathrm{O}$ and $\mathrm{N}$ are homogeneously distributed on the surface of the mild steel. This is a direct physicochemical evidence for the adsorption of the JM green inhibitor on the steel surface.

\section{CONCLUSION}

For the first time the homogeneous adsorption of the ethanolic extract of Jacaranda
Mimosifolia green inhibitor is evaluated and visualized. The efficiency of the inhibitor is evaluated by different methods including gravimetric weight loss and electrochemical studies. The thermodynamic parameters and the Langmuir adsorption isotherm indicated that the inhibitor acts via physical adsorption mechanism. Further, energy dispersive $X$-ray spectral mapping indicated that the inhibitor molecules are homogeneously distributed on the surface of the steel.

\section{ACKNOWLEDGEMENT}

Kesavan Devarayan and Monikandon Sukumaran thank College of Fisheries Engineering, Tamil Nadu Fisheries University for motivation towards research. Kavitha Rose thanks the management of Dhirajlal Gandhi College of Technology for their encouragement for research. Sankar A and Kavitha $R$ as well thank the management of Kandasamy Kandar's College for their support for research.

\section{REFERENCES}

1. Raja, P.B.; Mathur, G.S. Mater. Lett. 2008, 62, 113-116

2. Kesavan, D.: Gopiraman, M.; Sulochana, N. 7. Chem. Sci. Rev. Lett. 2012, 1, 1-8

3. Kesavan, D.; Muthu Tamizh, M.; Gopiraman, M.; Sulochana, N.; Karvembu, R. J. Surfact. Deterg. 2012, 15, 567-576

4. Kesavan, D.; Muthu Tamizh, M.; Sulochana, N.; Karvembu, R. J. Surfact. Deterg. 2012, 15, 751-756

5. Rajeswari, V.; Kesavan, D.; Gopiraman, M.; Viswanathamurthi, P. J. Surfact. Deterg. 2013, 16, 571-580

6. Kesavan, D.; Parameswari, K.; Lavanya, M.;
Beatrice, V.; Ayyannan, G.; Sulochana, N. Chem. Sci. Rev. Lett. 2014, 2, 415-422

Trevino-Cordero, H.; Juarez-Aguilar, L.G.; Mendoza-Castillo, D.I.; Hernandez-Montoya, V.; Bonilla-Petriciolet, A.; Montes-Moran, M.A. Ind. Crops Prod. 2013, 42, 315-323

8. Kavitha, R.; Byoung-Suhk, K.; Kalyanaraman, R.; Sankar, A.; Kesavan, D. J. Mol. Liq. 2016, 214, 111-116

9. Kavitha, R.; Kesavan, D.; Sankar, A. Chem. Sci. Rev. Lett. 2014, 3, 200-209

10. ASTM-G31-72, (2004) Standard practice for laboratory immersion corrosion testing of metals. Annual book of ASTM Standards, 
Philadelphia

11. Gopiraman, M.; Selvakumaran, N.; Kesavan, D.; Karvembu, R. Prog. Org. Coat. 2012, 111, 104-111

12. Tang, L.; Li, X.; Mu, G.; Li, L.; Liu. G. Appl. Surf. Sci. 2006, 252, 6394-6401

13. Ali, S.A.; Al-Muallem, H.A.; Saeed, M.T.; Rahman, S.U. Corros. Sci. 2008, 50, 664-
675.

14. Quartarone, G.; Bonaldo, L.; Tortato, C. Appl. Surf. Sci. 2006, 252, 8251-8257.

15. Hong, J.H.; Lee, S.H.; Kim, J.G.; Yoon, J.B. Corros. Sci. 2012, 54, 174-182.

16. Riggs, O.L. Corrosion Inhibitors, $2^{\text {nd }}$ ed., C. Nathan, Houston, TX, (1973) 43. 